\title{
Research on China's Financial Support for Scientific and Technological Innovation
}

\author{
Jun $X U^{1, a}$, Ling JIANG ${ }^{2, b,{ }^{*}}$ \\ ${ }^{1}$ Guangdong Productivity Center, Guangzhou, China \\ ${ }^{2}$ School of Economics and Trade, Guangdong University of Foreign Studies, Guangzhou, China \\ a e-mail:shwdy@qq.com, b e-mail: jljl126@126.com \\ *corresponding author
}

Keywords: Scientific and technological innovation, Financial support, Transformation of scientific and technological achievements.

\begin{abstract}
Science and technology is the key factor of economic growth, while finance support is an important impetus to the development of scientific and technological innovation, and the organic combination of technology and finance greatly improve the speed of scientific and technological achievements into high efficiency productivity. Based on the successful experience of developed countries, the authors put forward countermeasures and policy suggestions on the problems of financial support for scientific and technological innovation.
\end{abstract}

\section{Introduction}

Since the reforming and opening up in 1978, China's economy has advanced by leaps and bounds. With the rapid development of science and technology, the scientific and technological innovation is essential for China to keep sustainable development. Science and technology innovation in great demand of capital, request the financial system can provide high enough efficiency, large enough financial support. The development of technology and innovation cannot be separated from the financial support. In order to achieve the sound development of science and technology, science and technology and financial must be well combined. At present, many China's high-tech small and medium-sized enterprises (SMEs), are faced with finance problems, and become the obstacle of the development of science and technology. The development of technological and financial innovation plays an increasingly important role in economic growth, based on the experience of financial support scientific and technological innovation in the developed countries, and combining with China's actual situation on the support of scientific and technological innovation seems particularly important.

\section{Mechanism of Financial Support on Scientific and Technological Innovation}

Scientific and technological innovation has become the core impetus to a country, especially to a developing country, and how to support science and technology innovation is an important problem in China. Technology innovation and related activities not only directly create wealth for the social economy, providing various technical consultation, investment and financing services and other products, but also indirectly for the enhancement of social economy sustainable development capacity to provide basic protection. Due to high input of technological innovation, the China's high-tech SMEs generally are facing with financial difficulties. Funding is not only the primary factor hindering the development of China's high-tech SMEs, but also the most important factor affecting enterprises' independent innovation during the transition period. The technology being developed from $R \& D$ to the output of efficient productivity is a long process and at high risk, the low transformation rate is a serious problem in China. The average rate of conversion for China's scientific and technological achievements is only $20 \%$, and that of the industrialization is less than $5 \%$, that of patent technology trading is only 5\%, far below the level of developed countries. This leads to a lack of support for innovation. To get the commercial financial institutions investment 
loans is quite difficult, which is another reason for China's high-tech SMEs' financing problem. Innovation cannot be run without the financial support, but how the finance to support science and technology innovation is a problem. Innovation includes four phrases: seed, growth, expansion, maturity. The financial support is essential for the four phrases; the huge demand for funds is done only through the financial intermediary. Science and technology innovation of the capital formation mechanism is promoted by financial intermediary. It optimizes financial policy and allocates the interests according to the commercial finance competition mechanism for the optimal allocation of resources and capital formation, and eventually to provide adequate financial support for innovation.

\section{Experience of Developed Countries}

In the era of knowledge economy, science and technology develops rapidly and its leading role in promoting the development of a country has become increasingly prominent. The competitive advantage of a country has shift from recourses and cost to the technology. To maintain the persistent competitiveness, innovation has become the first choice for a country. Through a long-term exploration, developed countries have accumulated various methods and experience of stimulating technological innovation which are in line with their national conditions and distinctive. The world average level of R\&D investment accounted for $1.6 \%$ percent of global GDP. The rate of developing countries is about $1 \%-2 \%$ while that of developed countries is about $2.5 \%-3 \%$. Developed countries are paying more attention on R\&D and technological innovation in recent years. According to the experience of developed countries, the economic growth mostly counts on the innovation, they regard the strengthening of scientific and technological innovation as a national strategy and focus on enhancing the national innovation capacity and international competitiveness, and they have established a perfect technological innovation system. Take Japan and America as examples.

The United States is the most technologically advanced country in the world. Seventy percent of its economic growth comes from the scientific and technological innovation. The acquisition of strong scientific and technological strength is bound up with the support of the sound financial system, which is led by financial markets. The United States has strong national scientific and technological innovation capacity; in addition to its huge investment for R\&D expenditures, rather than government research management system, the policies of technology and industry as well as the Macro and Micro management and operation mechanisms of institutions, enterprises and universities. Among its scientific and technological innovation, more than half are born in the small business, thanks to the United States set up the specialized institutions of policy-oriented financing services for small business - Small Business Administration(abbreviation is SBA). The United States credits the success to its developed capital market, the most developed stock market system. The top of the Stock Exchange market is NYSE and NASDAQ, NYSE locates in the global blue-chip market, NASDAQ is mainly growth-oriented enterprise. At present, the NASDAQ market has become the incubator of innovation in the United States, according to statistics, more than $80 \%$ of high-tech listed companies are listing and trading on NASDAQ. The developed capital market allows Banks to SBA loan guaranteed for the enterprise as collateral, sell bonds in the bond market to accelerate the recovery of funds in order to improve the liquidity of banks' assets.

The total GDP of China surpassed that of Japan to become the second in 2010, but it does not deny the fact that Japan is a big country of economic and technological power, and Japan has made a lot of scientific and technological achievements. These achievements are closely related to the financial system based on policy finance. Japan's support for innovation is mainly through the bank as the leading indirect financing system, forming the powerful policy financial support system for promoting innovation, to provide financial support to technological enterprises. Japan has established many policy financial institutions, such as the Export-Import Bank, Development Bank, and SME Credit Insurance public library, to support science and technology enterprises by government grants, financial allocation and issue bonds. In addition, Japan's commercial bank system of large financial institutions and a lot of local small and medium-sized financial institutions co-existing, perfect credit 
guarantee system and well-developed venture capital market also promote the Japan's scientific and technological innovation and progress.

\section{Current Situation of China's Technology Finance}

Science and technology innovation processes need over a long period of investment, and bear the risk of failure. In our country, the motherboard market threshold is high, process is complicated, cycle is long, cost is high, and open door mainly to the large blue-chip companies, not to the majority of high-tech SMEs. The level of China's securities market is single, mainly for the Shenzhen and Shanghai main board market, small and medium-sized enterprise board(SME) affiliated with the Shenzhen stock exchange, compared with foreign Growth Enterprise Market (GEM), the listing threshold is high, mechanism is rigid, and does not have the financing function. Transfer mechanism between the motherboard, the SME board and the agency share transfer system has not been established and cannot form an effective interaction. In this way, the small and medium-sized innovative enterprise cannot obtain sufficient market opportunities from the capital market, the stock market cannot provide an effective exit channel for the venture capital, so it cannot be well positioned to meet the high demand of funds for technological innovation. Diversification requirements of investment and financing are still a lack of attraction to both sides. On the other hand, the imperfection of capital market has seriously hampered the efficient introduction and development of venture capital, thus restricting further expansion of China's venture investment capital, and indirectly hinders the sustainable development of scientific and technological innovation.

China's financial system is based on bank; financial assets and financial business are mainly in the four state-owned commercial banks. China's financial institution, with its profit-making target, give their support primarily to large-scale scientific and technological innovation projects, rarely to the small technology projects, resulting in excessive investment in large-scale technology projects and lack of investment in small technology projects, but the achievements of small technology project often turn into large-scale technology projects. Scientific and technological innovation, especially scientific innovation, as well as the technology innovation, which is in the seed stage and venture period, they have specialized and complex nature, belonging to the "experts information" rather than "local information". With the lack of effective intermediaries, banks can not assess the process and result of innovation accurately, and cannot effectively guard against credit risk, thus reluctant to get involved.

Although China has increased investment in technology year by year, the transformation of scientific and technological achievements is not satisfied. Scientific and technological achievements is the follow-up tests with the use of the value of scientific and technological achievements in scientific research and technology to improve productivity, development, deployment, diffusion, until the formation of new products, new processes, new materials, new industrial activities. Scientific and technological achievements conversion rate is an important index to measure the technological level of a country. Compared with the developed countries, China's scientific and technological achievements conversion rate is low, and technological achievements conversion have a direct impact on economic growth and the development of science and technology. China's scientific and technological achievements conversion rate is about $25 \%$, the real industrialization is less than $5 \%$, with the developed countries $80 \%$, the gap is too far.

\section{Policy Suggestions}

Firstly, the science and technology policy bank should be established when the timing is right. Owing to high-risk, commercial banks don't provide adequate financial support to the SMEs. At present, the main forms of the domestic specialized banks for SMEs: the first one is in the form of commercial bank branch, for example, high-tech branch of Chengdu bank and Chengdu high-tech branch of China construction bank are approved by China banking regulatory commission as technology bank in 2009; the second one is initiated the formation of share-holding system, set up new market operation pattern of financial institutions, such as is accelerating the preparation of the 
"Guangdong science and technology development bank". However, due to the initial stage, lack the supervision of the science and technology bank system. Policy bank is meant that established by the government, equity participation or guaranteed, not profit-oriented, specifically to carry out the government's social and economic policy or intention, directly or indirectly engaged in policy financing activities in specific business field, and serve as the financial institutions for government economic development, promoting social progress and macroeconomic management tool. Three policy banks, China development bank, Export-import bank of China and Agricultural development bank of China, have contributed to the development of China's economy. The government as the main investor identity established the science and technology policy bank, through the policy guidance, encourage and drive for the cooperation with risk investment institutions, provide financial platform collecting the social money to help promising technology of small and medium-sized enterprise, contributing to the social economic development.

Secondly, scientific and technological intermediary service institutions should be vigorously developed, so as to improve the science and technology conversion rate. In the process of science and technology innovation, scientific and technological intermediaries provide effective and timely communication to bridge the innovation supplier and demander, also for science and technology and economic docking provide entry. Thus in science and technology innovation system of each subject in the development of internal interaction, and information, technology, talent, capital, etc, various kinds of the flow of information the scientific and technological agency plays a prominent interactive sports service efficiency. Science and technology achieves its commodity property through the achievements into productivity. Scientific and technological intermediary service is the bridge to promote the circulation technology and the development technology, accelerate the transformation of scientific and technological achievements, which is the product that market economy and science and technology develops to a certain stage, fully reflects that the scientific and technological intermediary service institutions are important part of the market economy system. To use scientific and technological agency role of bridge and link, and promote the innovation of science and technology achievements conversion rates, the scientific and technological agency service system must be established and perfected.

Thirdly, develop multi-level capital market, providing good environment for science and technology. Science and technology innovation is divided into four stages: seed, growth, expansion, maturity, these four stages are different in needs, nature and the amount of fund. The funds alone from bank are inadequate to support for innovation; there is great uncertainty that it can be turned to the market products in the early science and technology innovation, for-profit commercial banks don't want to put large money into early scientific and technological innovation, so it is an urgent need to develop multi-level capital market. The multi-level market plays an important role in financing at science and technology innovation, some European countries of technology innovation of proportion of direct financing has reached to above $80 \%$, while the proportion is only around $3 \%$ in China, coupled with the development of bond market and equity market is not balanced, so it is difficult to meet the needs of the science and technology innovation. Through the development of multi-level capital market, it can promote technology innovation to proceed smoothly, the venture capital into the innovation through the multi-level capital market can exit science and technology enterprises by increasing capital and transferring equity, after the science and technology enterprises grow gradually expand, in this way, the original technology enterprises' capital is not reduced, and will not affect its normal operation. The multi-level market can also provide sufficient information for more investors to make investment and financing to achieve full information status, which can form an effective supervision mechanism, and improve overall efficiency of the science and technology innovation.

The above briefly analyzed the mechanism of the financial support for science and technology innovation, and discussed China's current situation in this field combined with the experience of the developed countries. Accordingly, we put forward some suggestions to better support the science and technology innovation. Science and technology innovation is an enormous project. Finance and technology are mutually primitive other than unilaterally effective. Science and technology 
innovation cannot make improvements without the financial support and so does the finance. In order to make good combination of finance and technology, it is necessary to balance the development of both. However, science and technology and finance are not mutually adaptable at the present. Financial system, especially the capital market in China, cannot meet the needs of the development of science and technology innovation. So we should speed up to establish and perfect our country's single capital market, strengthen the construction of the policy finance and support the development of intermediary service agency of science and technology.

\section{Acknowledgement}

This research was financially supported by the Department of Education of Guangdong Province (Grant No. 2017WTSCX027).

\section{References}

[1] Du Yue-ping, Ma Jing-jing. Research on Satisfaction of Financial Policy on Technology Innovation and Entrepreneurship[J]. Science \& Technology Progress and Policy, 2016(9), pp.96-102. ( In Chinese )

[2] King R, Levine R. Finance, enterpreneurship and growth: Theory and evidence[J]. Journal of Monetary Economic, 1993 (3) :513-542.

[3] Liu Jia-shu, Jian Li-rong. The measurement of scientific and technological achievements into the efficiency and influencing factors [J]. Science \&Technology Progress and Policy, 2010(10), pp.113-116. ( In Chinese )

[4] Tao Ding, Hanhui Hu. The international comparison of financial support for Innovation and path design [J]. Soft Science, 2009(3), pp.50-54. ( In Chinese )

[5] Zheng Yu-hang , Li Zheng-hui. Research on the Effectiveness of China's Financing Service for Technology Innovation [J]. China Soft Science, 2015(7), pp.127-136. ( In Chinese ) 